\title{
Activation of Different Anterior Cingulate Foci in Association with Hypothesis Testing and Response Selection
}

\author{
R. Elliott* and R. J . Dolan*, \\ *Wel I come Department of Cognitive Neurol ogy, Institute of Neurol ogy, 12 Queen Square, London WC1N 3BG, United Kingdom; \\ and TRoyal FreHospital School of Medicine, Rowland Hill Street, London NW3 2PF, United Kingdom
}

Received December 29, 1997

\begin{abstract}
Much everyday behavior is implicitly guided by hypotheses about the world which are monitored and updated in the light of changing circumstances. The process of translating these hypotheses into behavior typically involves implementing choices, often based on incompletely specified information. The present study aimed at modeling these processes to determine the neural substrates of hypothesis testing and, in particular, how these are modulated by the requirement to make choices. We used positron emission tomography to study six right-handed volunteers performing an insoluble hypothesis testing task in which subjects attempted to identify a rule determining which of two black and white checkerboard stimuli was correct. This task was compared with a control task matched for perceptuomotor requi rements, but involving no hypothesis testing. Both tasks were performed with or without a requirement to make a choice. Structures activated in association with hypothesis testing included the cerebellum, left anterior cingulate, right precuneus, right thalamus, and left inferior frontal gyrus. The requirement to choose a response was associated with activation of the left anterior cingulate and right lateral orbitofrontal cortex. A significant modulation of activation associated with hypothesis testing was observed in the anterior cingulate region that was also activated by making a choice. These findings are discussed in terms of the neural substrates of complex "executive" tasks. We argue that the precise cognitive parameters of such tasks, and specifically the requirement to implement decisions in actual behavior, are critical in determining the associated neural response. 1998 Academic Press
\end{abstract}

\section{INTRODUCTION}

Laboratory tests of higher order cognition are usually constrained and uniquely soluble. The real world, however, is open-ended and decisions are frequently made with incomplete information. Novel problems engender the generation and testing of predictive hy- potheses to guide behavior until experience suggests appropriate alternative hypotheses. The weighting attached to hypotheses varies from minimal, in the case of initial guesswork, to something akin to belief with repeatedly affirmed hypotheses. As Cohen (1972) describes it "Man supposes, guesses and reasons; he makes estimates and inferences. . . . Hetakes risks and arrives at decisions in the light of partial information ... he has to test his private hypotheses. And he has to act." The crucial point is that hypotheses and beliefs about the world are ultimately expressed in behavior. In incompletely specified situations, a choice of behavior requires commitment to a current hypothesis (Cherry, 1979) which embodies an element of risk, since the ensuing outcome is unpredictable and may or may not be desired.

In the present study, we used positron emission tomography (PET) to study the neural responses associated with hypothesis testing and, in particular, choice implementation and their interaction. We used a complex nonverbal task in which subjects attempted to determine a rule governing which of two checkerboard patterns was correct. The task was insoluble and, consequently, subjects made judgments on the basis of incompletely specified information. Subjects were provided with intertrial feedback to monitor and update their hypotheses. While the task used in this study was designed with an emphasis on generating and testing hypotheses, it included other subprocesses, particularly working memory, response monitoring, and reasoning.

The hypothesis testing task we used is an example of the type of task usually subsumed by the term "executive." Previous functional imaging studies have described neural activations associated with such executive tasks. The working memory component of these tasks has usually been related to activation of the dorsolateral prefrontal cortex (DLPFC) (e.g., Goldberg et al., 1996; Petrides et al., 1993; Owen et al., 1996; Andreasen et al., 1992; Baker et al., 1996). Significant activations are also commonly reported in anterior 
cingulate, as well as more posterior and subcortical regions, including premotor cortex, superior parietal cortex, occipital cortex, basal ganglia, thalamus, and cerebellum. We therefore predicted that the complex hypothesis testing task in the present study would be associated with activations within a similar network of prefrontal, posterior, and subcortical structures.

When hypotheses are used to guide and regulate behavior they necessarily engender a choice. Neuropsychological evidence indicates that these two components are dissociable in that the ability to understand and describe the parameters of a particular situation (i.e., hypotheses about a situation) can be dissociated from the ability to choose on the basis of this understanding (Damasio, 1994; Bechara et al., 1994, 1996). The key aim of this study was to address the choice or decision component separately by considering the requirement of response selection as a variable of interest. Thus, neural activity associated with hypothesis testing was compared with and without the requirement to make a choice.

Response selection has previously been studied explicitly under the constraints of cued and self-generated action (Frith et al., 1991). Choosing, compared to executing a cued response, engages the DLPFC and the anterior cingulate. Frith et al. (1991) argued that the cingulate component of this response represented selection for action, a view supported by Paus et al. (1993), who identified output-specific neural responses within distinct subregions of the anterior cingulate. However, making a choice may involve not only response selection but also a value-based component and an element of risk related to the possibility of making a correct or incorrect choice. Neuropsychological evidence suggests a role for orbitofrontal cortex in risk-taking behavior (Damasio, 1994; Bechara et al., 1994). In the present study, we therefore hypothesized that the requirement to make a choice would be associated with activation in similar regions as well as the anterior cingulate cortex. A final and crucial prediction was that activation associated with hypothesis testing would be significantly modulated by the requirement to make a choice.

\section{METHOD}

\section{Subjects}

Six right-handed male volunteers ages between 22 and 37 were recruited. Subjects who reported any neurological or psychiatric history were excluded, as were subjects with any evidence of abnormality on structural a MRI scan. The study was approved by the local hospital ethics committee, and permission to administer radioactive substances was obtained from the Administration of Radioactive Substances Advisory Committee (UK). Informed written consent was obtained prior to the study.

\section{Cognitive Activation Paradigm}

This experiment was a $2 \times 2$ factorial design (Fig. 1a) with requirement to generate and test hypotheses as one factor and requirement to make a decision as the other factor.

\section{Factor 1: Task Requirement}

Hypothesis-testing task. In this task subjects were presented with a series of pairs of different $6 \times 6$ checkerboards with black and white squares, the locations of which were selected at random for each stimulus (see Fig. 1b). It was essential to use pairs rather than single stimuli because of the choice requirement described below. Each pair was displayed for $5 \mathrm{~s}$ before disappearing. Subjects were then prompted to make a manual response (see below) and then a new pair was presented with no fixed relation to the preceding pair. A total of 10 pairs were presented during each experimental block and subjects were instructed to try to work out a rule governing which of each pair was correct. Subjects were told that this rule could relate to any aspect of the spatial configuration of the checkerboards. The task requirement was to generate a hypothesis and then test and update it on the basis of information about which checkerboard was correct. In reality there was no hypothesis; the assignment of the correct checkerboard was entirely arbitrary. This was to guard against subjects selecting the right hypothesis at the outset and subsequently not engaging in the updating process. After each block subjects were asked to explain how they had approached the task and which hypotheses they had generated and tested. They were tol d that the task was extremely difficult and not readily soluble.

Control task. In this task, subjects were again presented with pairs of different checkerboards but this time, the pair was the same on each trial. Subjects were told to watch the screen until the pair disappeared, which was their signal to make a prompted response (see below). They were told that on each trial one of the checkerboards would be randomly assigned as correct and one as incorrect. There was no rule involved and, since the pair was the same each time with the correct one varying randomly, there was no possibility that subjects could be attempting to use a hypothesis driven approach to the task.

\section{Factor 2: Choice Requirement}

Both the above tasks were performed under two choice conditions.

Choice required. In this condition, subjects were required to select which of the pair of checkerboards was correct (making a choice on the basis of their current hypothesis in the hypothesis generation task, 


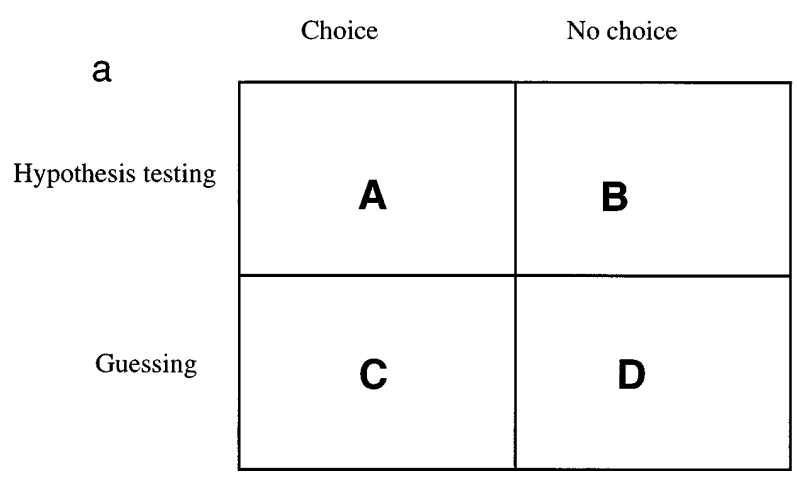

b
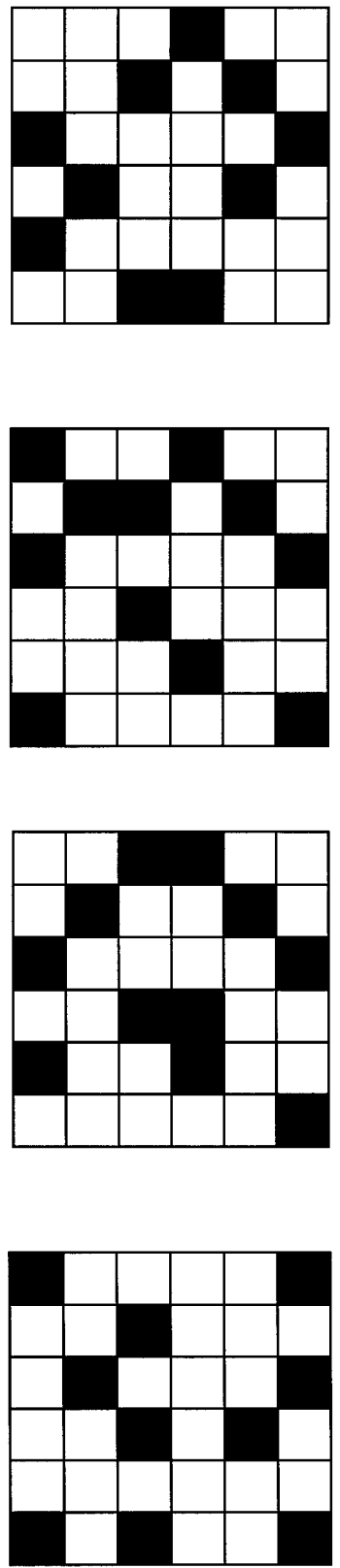
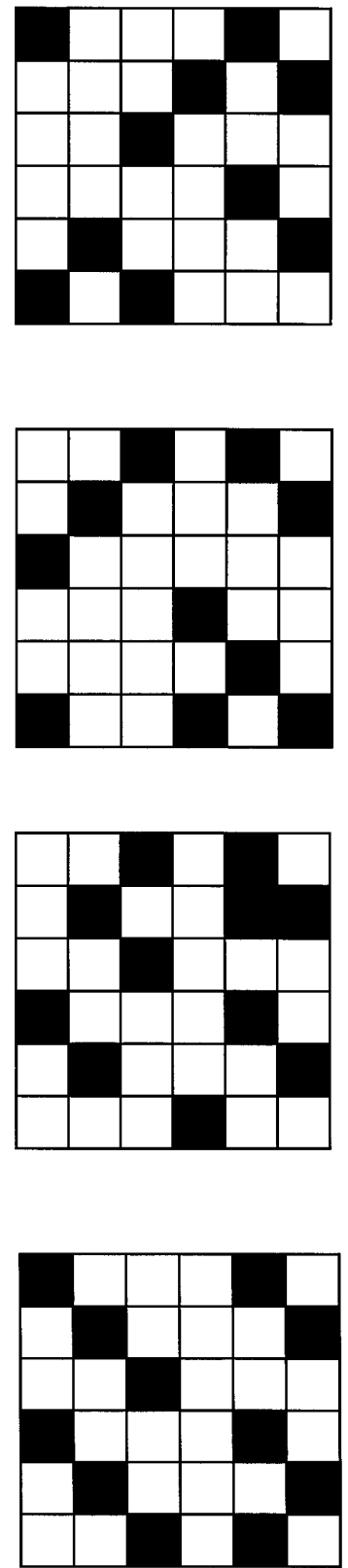

FIG. 1. (a) A graphical depiction of the $2 \times 2$ factorial design. (b) The checkerboard stimuli used in the hypothesis testing task. Shown is a typical series of pairs of stimuli which were presented serially to subjects who were required to use intertrial feedback to devel op a hypothesis determining which of each pair was correct. Typical hypotheses included "top left-hand corner filled," "two adjacent filled squares," “a diagonal run of filled squares," "the more symmetrical checkerboard," etc.

making a guess in the no-hypothesis task). The pair of checkerboards was replaced by the prompt "choose now" and subjects had to press a left- or a right-hand key. They were given feedback to this response, the word "correct" or the word "wrong." This feedback was actually random, on a 50:50 schedule, and it bore no relation to the subject's response.

No choice required. In this condition subjects were not required to make a decision. The prompt which replaced the checkerboards was "press left" or "press right" (the side determined at random) and subjects were simply required to make the specified response. The feedback was therefore always "correct." In the hypothesis-testing task under this condition, subjects were still required to generate and test hypotheses and knew that they would have to explain their hypotheses at the end of the block; however, they were not required to make a decision on the basis of their current belief.

During each scan, a series of 10 pairs of checkerboards was presented, beginning $10 \mathrm{~s}$ before scanning. 
Subjects were scanned 12 times and therefore performed three repetitions of each condition. The order of conditions was counterbalanced within and between subjects. Every individual checkerboard in the hypothesis testing task was unique, as was each pair used in a run of the control task.

\section{PET Scanning Technique}

Regional cerebral blood flow (rCBF) was measured with an ECAT HR + scanning system (CTI Siemens, Knoxville, TN) in 3D mode with septa retracted. For each scan, $555 \mathrm{MBq}$ of $\mathrm{H}_{2}^{15} \mathrm{O}$ was flushed through a venous cannula in the left antecubital vein with normal saline over $20 \mathrm{~s}$ at a rate of $10 \mathrm{ml} / \mathrm{min}$ by an automatic pump. After a delay of about $35 \mathrm{~s}$, a rise in counts could be detected at the head, peaking 30-40 s later, varying for individual subjects. The data were acquired during one 90 -s frame, beginning $5 \mathrm{~s}$ before the rising phase of the head curve. A total of 12 scans were performed at intervals of $8 \mathrm{~min}$. Correction for attenuation was made by performing a transmission scan with an exposed 68 Ge/68 Ga external ring source before each session. I mages were reconstructed by filtered back projection to give a resolution of approximately $6 \mathrm{~mm}$ at full width half-maximum (FWHM) and displayed in a $128 \times 128$ pixel format with 43 planes rendering the voxels approximately cubic.

\section{Data Analysis}

Data wereanalyzed using statistical parametric mapping (SPM 96; Wellcome Department of Cognitive Neurology, London, UK) implemented in MATLAB (Mathworks, Inc., Sherborn, MA) and run on a SPARC workstation (Sun Microsystems, Inc., Surrey, UK). Scans were realigned using the first as a reference and were subsequently transformed into a standard space corresponding to the ster eotactic atlas of Talairach and Tournoux (1988) using MNI templates (Montreal Neurological Institute). These normalized images were smoothed with a 12-mm FWHM isotropic Gaussian kernel.

Analysis of this factorial experiment was carried out using the general linear model. The conditions for each subject were specified in the appropriate design matrix which also included global activity as a confounding covariate and can therefore be considered an ANCOVA. Effects at each and every voxel (total search volume for all comparisons was 248,508 voxels or 1506.7 resels) were estimated according to the general linear model, and regionally specific effects were compared using linear contrasts. The resulting set of voxel values for each contrast constituted a statistical parametric map of thet statistic (SPM $\{\mathrm{t}\}$ ) which was then transformed to the unit normal distribution, SPM $\{Z\}$. Statistical inferences were based on the theory of random Gaussian fields (Friston et al., 1995). Strictly, firm conclusions can only be drawn about areas where activity survives correction for multiple comparisons. However, in line with accepted functional neuroimaging convention, we have descriptively reported activations significant at $P<0.001$ uncorrected, corresponding to $Z=3.09$, although strong conclusions cannot be drawn about these regions in the absence of correction for multiple comparisons.

The stereotactic coordinates of Talairach and Tournoux (1988) are used to report the observed activation foci. However, the descriptions of the anatomical localization of these foci were determined using the averaged structural MRIs of the group and the atlas of Duvernoy (1991). We have found that this method provides a more accurate localization than the Talairach and Tournoux atlas (1988).

\section{RESULTS}

\section{Performance Data}

All six subjects attempted to perform the hypothesis testing task in all scans under this condition. When asked to describe the hypotheses tried, all subjects discussed at least two, and more usually three or four, plausible hypotheses which had been tested during each scan. A statistical comparison of the number of hypotheses tested under the choice and no-choice condition revealed no significant differences $(t=0.32$, $P=0.75)$.

\section{Activations Associated with $\mathrm{H}$ ypothesis Generation and Testing}

This comparison represents the main effects of task requirement (the two hypothesis-testing conditions, with and without choice, compared to the two guessing conditions, with and without choice, $(A+B)-(C+D)$ in Fig. 1a) (see Fig. 2a and Table 1).

rCBF increases (activations) were observed in the cerebellar vermis and cerebellar hemispheres, the dorsal bank of the left anterior cingulate (BA 32), the right precuneus (BA 7), the right thalamus, and the left inferior frontal gyrus (BA 44/45). The activations in right cerebellar vermis and left anterior cingulate reached significance at $\mathrm{P}<0.05$, corrected. Relative rCBF decreases (deactivations) were observed in the left inferior parietal cortex (BA 40), right medial temporal gyrus (BA 21), posterior cingulate (BA 24), anterior frontal cortex (BA 10), and posterior caudate. The deactivations in inferior parietal cortex reached significance at $\mathrm{P}<0.05$, corrected.

\section{Activations Associated with Making a C hoice}

This comparison represents the main effect of the requirement to make a decision across the two tasks 
(the two choice conditions, hypothesis testing and guessing, compared to the no-choice conditions, hypothesistesting and guessing, $(A+C)-(B+D)$ in Fig. 1a) (see Fig. 3a and Table 2).

Increases in rCBF (activations) associated with making a decision were observed in the anterior cingulate (BA 32/24) and the right anterior lateral orbitofrontal cortex (BA 11). The cingulate locus in this comparison was anterior and ventral to that in the main effect of the hypothesis testing task (see Figs. 2b and 3b). Adjusted blood flow values showed different profiles in the two loci (see Figs. 2c and 3c). Relative decreases in rCBF (deactivations) were seen in the medial temporal gyrus bilaterally (BA 37), right inferior temporal gyrus (BA 20), posterior cingulate (BA 29), and medial prefrontal cortex (BA 10). However, none of these rCBF changes reached a corrected significance level.

\section{Modulation of $\mathrm{H}$ ypothesis Testing by the Requirement to Make a Choice}

This comparison represents the interaction in the factorial design and reflects the modulation of the activation associated with hypothesis testing compared to guessing by the requirement to make a choice $((A-C)-(B-D)$ in Fig. 1a) (Table 3).

Differences in activation associated with making a choice in the hypothesis testing compared with making a choice in the guessing task were seen in the left anterior cingulate (BA 24), precuneus (BA 7), left medial temporal gyrus (BA 37), right lingual gyrus (BA 19), left medial occipital gyrus (BA 19), and right medial prefrontal cortex (BA 10). However, none of these $\mathrm{rCBF}$ changes reached a corrected significance level. There were noactivations significant at $P<0.001$ uncorrected associated with the reverse interaction.

\section{Activations Associated with Choice Implementation within the Individual Tasks}

These comparisons represent the simple main effects of choice in the analysis (hypothesis testing with choice compared to hypothesis testing without choice and guessing with choice compared to guessing without choice, (A - B) and (C - D) in Fig. 1a) (Table 4).

\section{Hypothesis-Testing Task}

Activations were seen in the left anterior cingulate (BA 32/24), right postcentral gyrus (BA 4), and bilateral precuneus (BA 7). Relative deactivation was seen in the posterior cingulate (BA 29).

\section{Control Task}

Activation was seen in the right orbitofrontal cortex (BA 11). Relative deactivations were seen in the left medial temporal gyrus (BA 37), medial prefrontal cor- tex (BA 10), and right inferior temporal gyrus (BA 28). The medial temporal gyrus deactivation reached significance at $\mathrm{P}<0.05$ corrected.

\section{Activations Associated with Task in the Presence/ Absence of Choice Requirement}

These comparisons represent the simple main effects of task in the analysis (Table 5), hypothesis testing with choice compared to guessing with choice and hypothesis testing without choice compared to guessing without choice, $((A-C)$ and $(B-D)$ in Fig. 1a).

\section{Choice Required}

Activations were observed in the same network as that activated by the overall main effect of hypothesis testing but the anterior cingulate activation extended more ventrally. The pattern of relative deactivation was much less extensive than that associated with the overall main effect. Deactivations were observed in the left inferior parietal cortex (BA 40), left posterior insula, and tail of the caudate nucleus on the left and right medial temporal cortex. However, none of these rCBF changes reached a corrected significance level.

\section{No Choice Required}

Activations were observed in the dorsal anterior cingulate (BA 32) and cerebellar vermis only. Relative deactivations were seen throughout the network associated with the overall main effect. However, none of these $\mathrm{rCBF}$ changes reached a corrected significance level.

\section{DISCUSSION}

The complex hypothesis testing task used in this study was associated with a widespread neural response in the bilateral cerebellum, left dorsal anterior cingulate, right superior medial parietal cortex (precuneus), right thalamus, and left ventrolateral frontal cortex. The key finding in view of the aims of this study was that implementing a choice was associated with activations in left anterior cingulate, ventral to that associated with hypothesis testing, and right lateral orbitofrontal cortex. Hypothesis-testing activations were modulated by the requirement to make a choice as shown by the significant interaction term, with the requirement to make a choice associated with augmentation of activation in the left anterior cingulate and inferior frontal gyrus and right premotor cortex, posterior parietal cortex, cerebellum, and right lateral orbitofrontal cortex.

A critical activation associated with the hypothesistesting task in this study was of the left dorsal anterior cingulate. There are a number of possible explanations for this, as the task is a complex one involving a number 
a
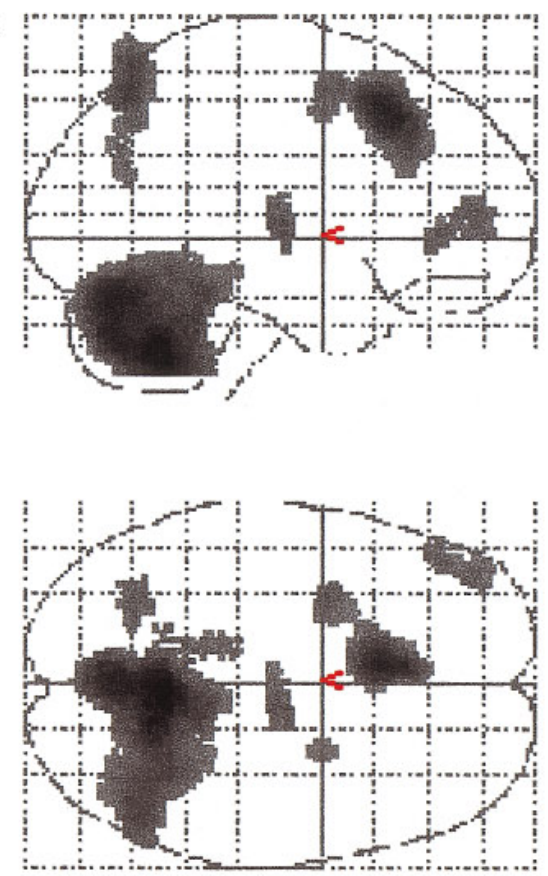

b

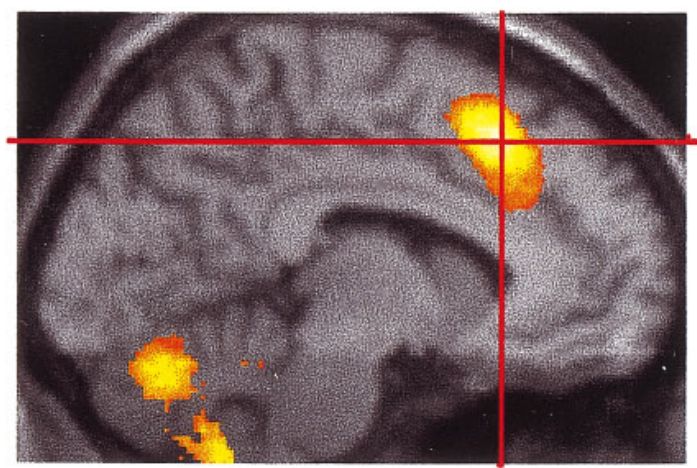

transverse

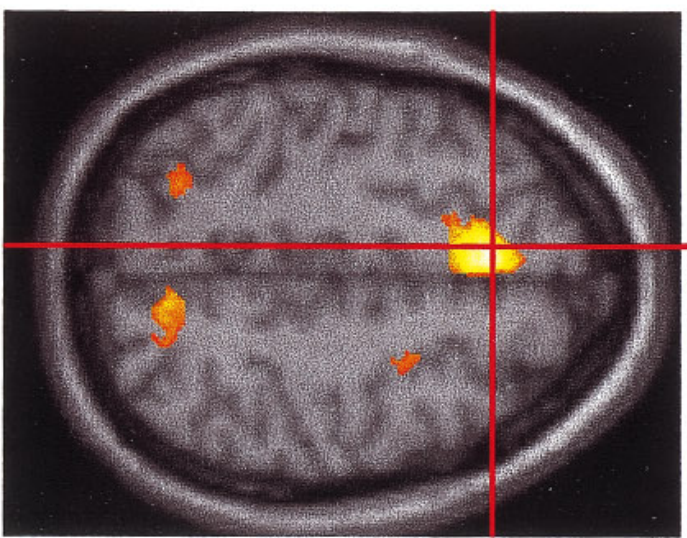

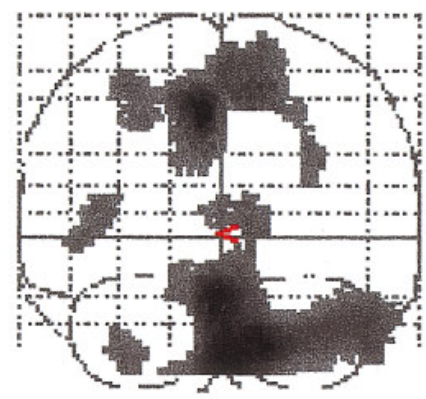

\section{coronal}
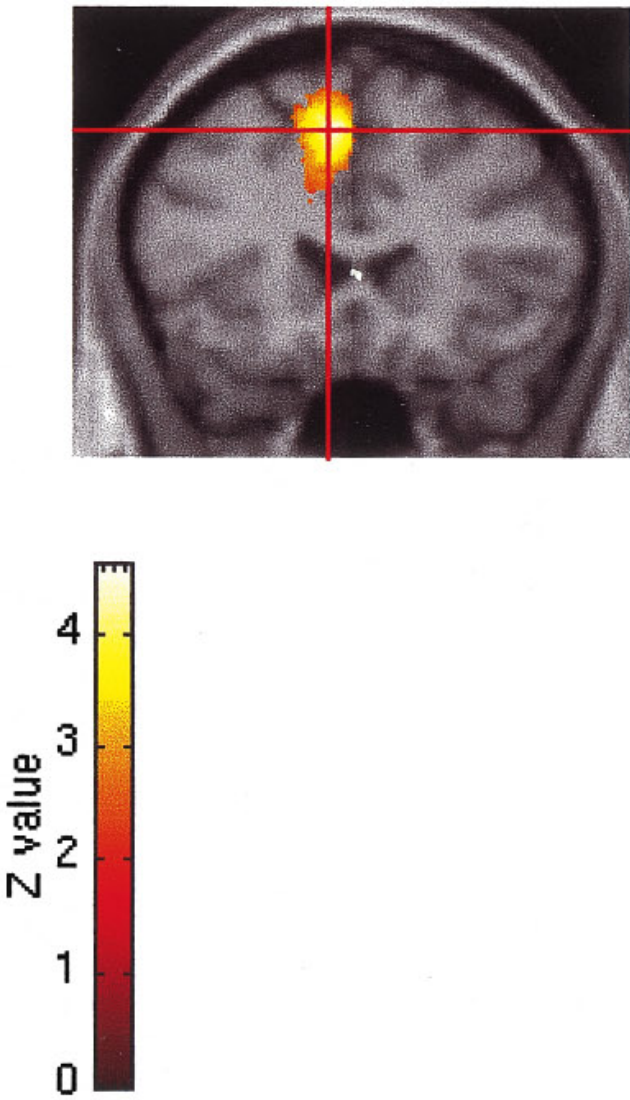

FIG. 2. Activations associated with hypothesis testing compared to guessing. (a) The statistical parametric map of the $t$ statistic (after transformation to a SPM $\{Z\}$ ) thresholded at $\mathrm{P}<0.001$. (b) This activation is shown rendered onto a standard MRI template and focused on the dorsal anterior cingulate. (c) Adjusted blood flow response in this anterior cingulate focus under the four experimental conditions. 
C

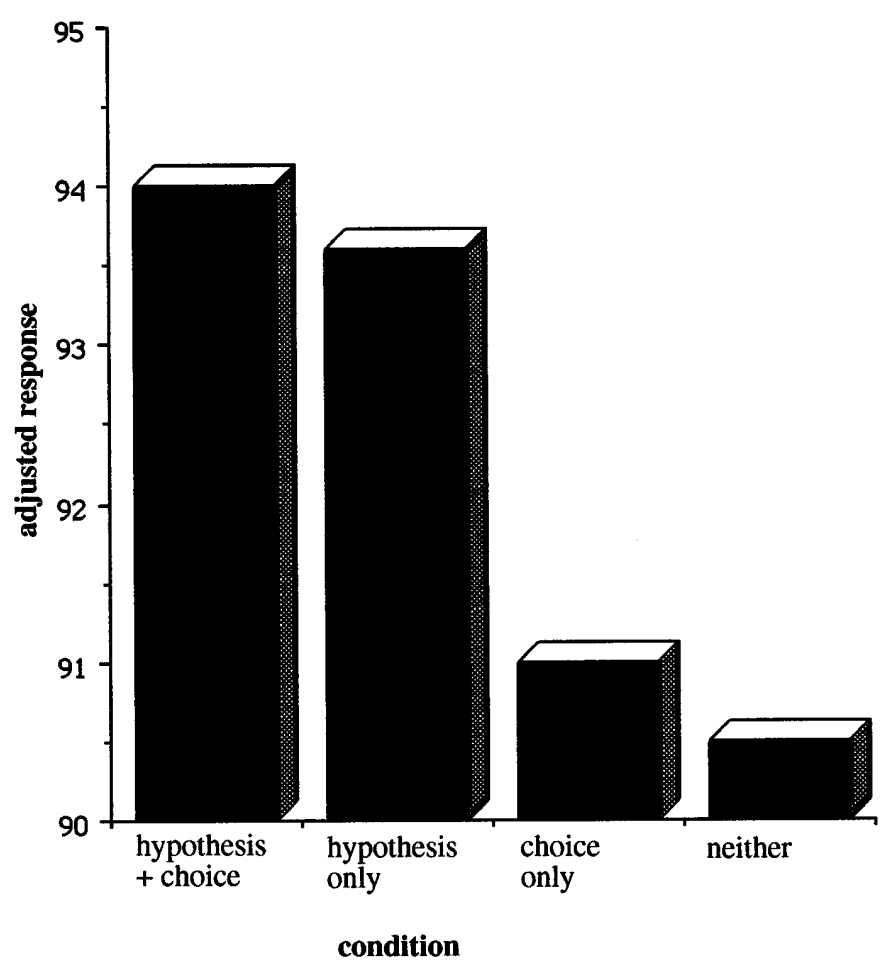

FIG. 2-Continued make a choice, where a more ventral focus of activation was noted than that associated with the hypothesistesting task. The choice conditions differ from the no-choice conditions in several ways, including the requirement to select rather than merely execute a prespecified response. There is also a subtle evaluative difference; in the choice conditions, subjects run the risk of making an incorrect response and receiving negative feedback. Ventral cingulate activation associated with choice was also seen in the interaction term, which represents the modulation of hypothesis task activation by the requirement to make a choice. Although the focus of this activation was not the same as the most significantly activated voxel in the main effect of choice, it was within thearea activated in association with making a choice. The simple main effects analysis and the adjusted blood flow values shown in Fig. $3 \mathrm{C}$ showed that significant activation in this ventral cingulateregion was morestrongly associated with making a choice in the hypothesis-testing than in the guessing task. Therefore, it is unlikely to be associated with response selection per se. It may, however, be involved in response selection in situations where selection is guided by internal cognitive representations rather than random guessing. This would be consistent with the suggestion of Paus et al. (1993) that anterior

\section{TABLE 1}

Coordinates of Significant rCBF ChangeAssociated with Hypothesis Testing (with and without Choice) Compared to Guessing (with and without Choice) activation has been associated with different aspects of working memory and planning (e.g., Baker et al., 1996; Courteney et al., 1996; Owen et al., 1996). The activation could also be inter preted as reflecting the selection of which of the possible competing hypotheses is attended to at a given point. Previous PET studies have suggested that this area may be involved when subjects are required to voluntarily generate words (Petersen et al., 1988) or motor responses (Frith et al., 1991). This selection is not confined to the output level of processing; the internal selection involved in detecting or noting an event is sufficient to activate the anterior cingulate (Posner et al., 1988). Anterior cingulate activity associated with selection has further been hypothesized to occur particularly in situations which require the modification of behavioral output in unpredictable situations (Paus et al., 1993), such as that in the present study. There is also evidence for increasing anterior cingulate involvement as the attentional demands of tasks are increased (Pardo et al., 1990; Corbetta et al., 1993). The hypothesis-testing task in this study is clearly more attentionally demanding than the control task.

The complexity of the task we used here does not allow us to be specific as to the exact role of the dorsal anterior cingulate. However, activation of the anterior cingulate was also associated with the requirement to

\begin{tabular}{|c|c|c|c|c|c|c|}
\hline \multirow{2}{*}{$\begin{array}{l}\text { Region of } \\
\text { activation }\end{array}$} & \multirow{2}{*}{$\begin{array}{l}\text { Left/ } \\
\text { right }\end{array}$} & \multirow{2}{*}{$\begin{array}{c}\text { Brodmann's } \\
\text { area }\end{array}$} & \multicolumn{3}{|c|}{$\begin{array}{l}\text { Talairach } \\
\text { coordinates }\end{array}$} & \multirow{2}{*}{$\begin{array}{c}\text { Z value } \\
\text { (3.09 for } \\
\mathrm{P}<0.001)\end{array}$} \\
\hline & & & $x$ & $\mathrm{y}$ & z & \\
\hline \multicolumn{7}{|l|}{ Relative activations } \\
\hline Anterior cingulate & $\mathrm{L}$ & 6 & -8 & 22 & 48 & $4.75^{*}$ \\
\hline $\begin{array}{l}\text { Precuneus } \\
\text { Inferior frontal }\end{array}$ & $\mathrm{R}$ & 7 & 14 & -64 & 56 & 3.89 \\
\hline gyrus & $\mathrm{L}$ & $44 / 45$ & -44 & 40 & 2 & 3.24 \\
\hline Thalamus & $\mathrm{R}$ & & 10 & -12 & 6 & 3.41 \\
\hline Cerebellar vermis & $R$ & & $\begin{array}{r}6 \\
-2\end{array}$ & $\begin{array}{l}-52 \\
-70\end{array}$ & $\begin{array}{l}-46 \\
-38\end{array}$ & $\begin{array}{l}5.14 * \\
465\end{array}$ \\
\hline Lateral cerebellum & $\begin{array}{l}\mathrm{R} \\
\mathrm{L}\end{array}$ & & $\begin{array}{r}24 \\
-32\end{array}$ & $\begin{array}{l}-54 \\
-60\end{array}$ & $\begin{array}{l}-38 \\
-46\end{array}$ & $\begin{array}{l}3.95 \\
3.25\end{array}$ \\
\hline \multicolumn{7}{|l|}{$\begin{array}{l}\text { Relative deactiva- } \\
\text { tions } \\
\text { Inferior parietal }\end{array}$} \\
\hline $\begin{array}{l}\text { cortex } \\
\text { Medial temporal }\end{array}$ & $\mathrm{L}$ & 40 & -64 & -30 & 24 & $5.94 *$ \\
\hline gyrus & $\mathrm{R}$ & 21 & 46 & 6 & -16 & 4.43 \\
\hline $\begin{array}{l}\text { Posterior cingulate } \\
\text { Anterior pre- }\end{array}$ & $\mathrm{L} / \mathrm{R}$ & 24 & -2 & -10 & 44 & 3.63 \\
\hline $\begin{array}{c}\text { frontal cortex } \\
\text { Posterior caudate }\end{array}$ & $\begin{array}{l}R / L \\
L\end{array}$ & 10 & $\begin{array}{r}2 \\
-26\end{array}$ & $\begin{array}{r}56 \\
-38\end{array}$ & $\begin{array}{l}18 \\
12\end{array}$ & $\begin{array}{l}3.58 \\
3.36\end{array}$ \\
\hline
\end{tabular}

Note. Activations are reported for descriptive purposes which reach a statistical threshold of $\mathrm{P}<0.001$ uncorrected, but those which reach corrected significance at $\mathrm{P}<0.05$ are marked $(*)$. 
a
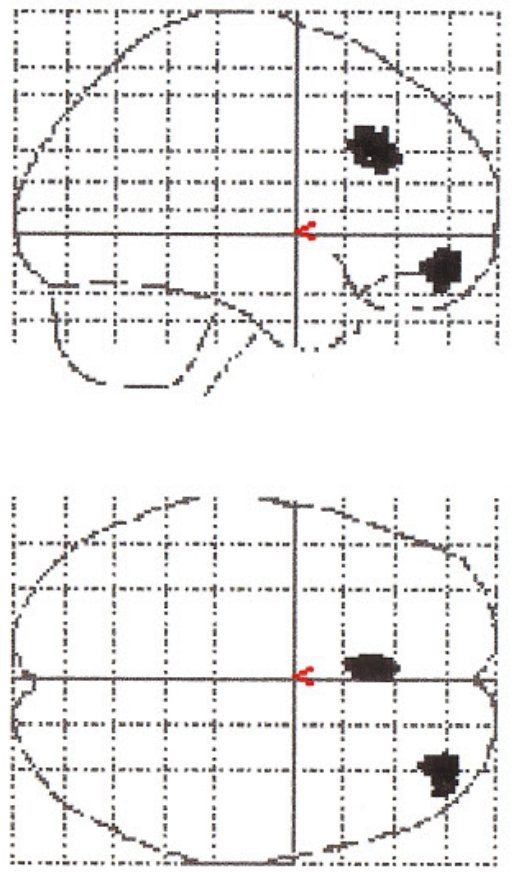

b

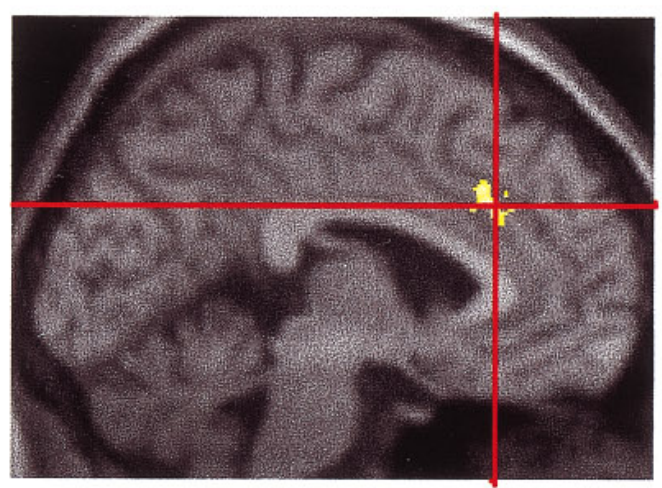

transverse

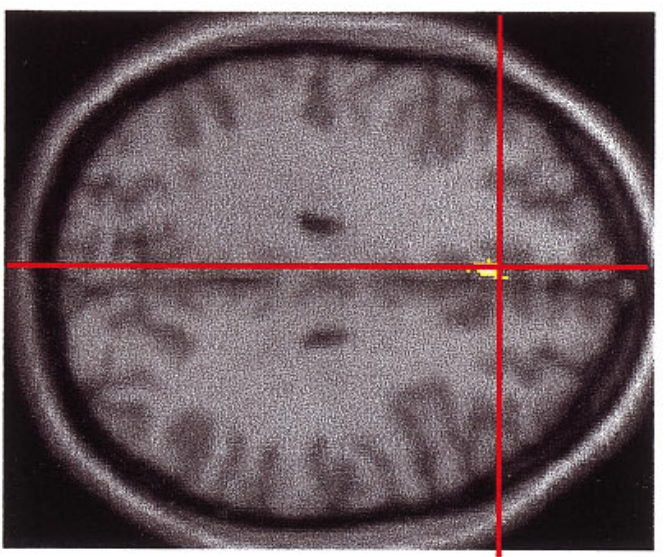

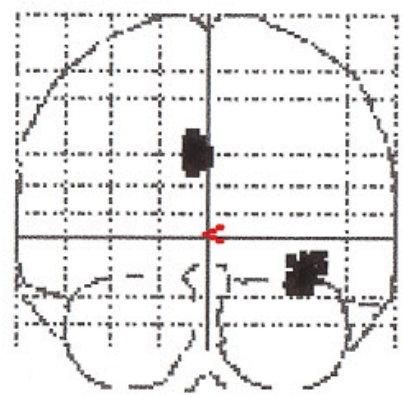

coronal
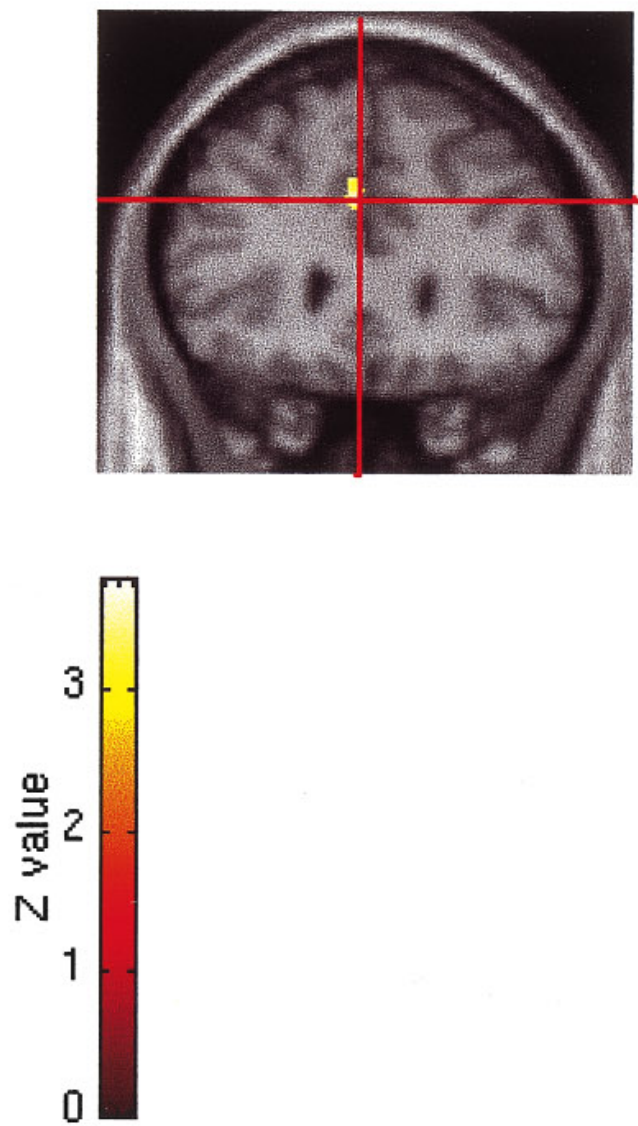

FIG. 3. Activations associated with the requirement to make a choice. (a) The statistical parametric map of the $t$ statistic (after transformation to a SPM $\{Z\}$ ) threshol ded at $\mathrm{P}<0.001$. (b) This activation is shown rendered onto a standard MRI template and focused on the anterior cingulate; note that this focus is relatively ventral to that shown in Fig. 2b. This activation focus is also associated with the modulation of hypothesis testing by decision-making and this interaction can be seen clearly in c. 


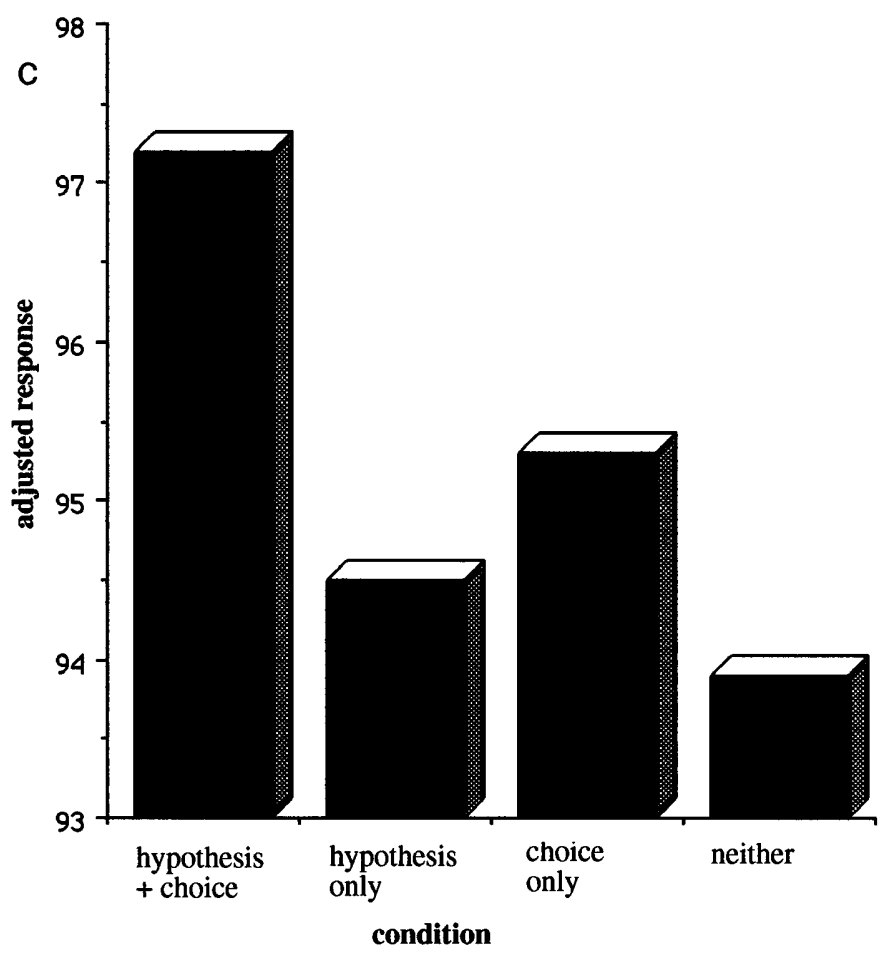

FIG.3-Continued

cingulate activation critically depends on the cognitive requirements related to the selection of a particular motor program. We suggest an alternative, and not mutually exclusive, explanation that ventral anterior cingulate activation in part reflects evaluative processing related to the emotional consequences of making a choice.

Our study has demonstrated a dissociation between two different foci within the anterior cingulate under different task conditions. A more dorsal region was activated in association with a complex executive function and a more ventral region specifically in association with making choices. This may represent a differ-
TABLE 3

Coordinates of Significant rCBF Change Associated with Modulation of Hypothesis Testing Compared to Guessing by the Requirement to Make a Choice

\begin{tabular}{|c|c|c|c|c|c|c|}
\hline \multirow{2}{*}{$\begin{array}{l}\text { Region of } \\
\text { activation }\end{array}$} & \multirow{2}{*}{$\begin{array}{l}\text { Left/ } \\
\text { right }\end{array}$} & \multirow{2}{*}{$\begin{array}{l}\text { Brodmann's } \\
\text { area }\end{array}$} & \multicolumn{3}{|c|}{$\begin{array}{l}\text { Talairach } \\
\text { coordinates }\end{array}$} & \multirow{2}{*}{$\begin{array}{c}\text { Z value } \\
\text { (3.09 for } \\
\mathrm{P}<0.001)\end{array}$} \\
\hline & & & $x$ & $y$ & z & \\
\hline \multicolumn{7}{|l|}{ Relative activations } \\
\hline Anterior cingulate & $\mathrm{L}$ & 24 & -6 & 14 & 26 & 3.09 \\
\hline $\begin{array}{l}\text { Precuneus } \\
\text { Medial temporal }\end{array}$ & $\mathrm{L}$ & 7 & -6 & -62 & 56 & 3.49 \\
\hline gyrus & L & 37 & -48 & -64 & 6 & 3.41 \\
\hline $\begin{array}{l}\text { Lingual gyrus } \\
\text { Medial occipital }\end{array}$ & $\mathrm{R}$ & 19 & 20 & -58 & -2 & 3.39 \\
\hline $\begin{array}{l}\text { gyrus } \\
\text { Anterior pre- }\end{array}$ & L & 19 & -38 & -76 & -8 & 3.25 \\
\hline frontal cortex & $\mathrm{R}$ & 10 & 6 & 68 & 18 & 3.58 \\
\hline
\end{tabular}

ence between two types of selection process, namely selection of a hypothesis to guide behavior compared with selection of a specific behavior. It may also reflect differences between purely cognitive aspects of processing in the dorsal region and more emotive aspects in the ventral region. This view is supported by the functional divisions which have been identified in the anterior cingulate. The dorsal region has connections with the dorsolateral prefrontal cortex (Pandya and Yeterian, 1996) and reciprocal connections with motor and premotor cortices (Dum and Strick, 1991; Morecraft and Van Hoesen, 1992). The ventral region is interconnected mainly with other classical limbic structures, including the amygdala (Vogt and Pandya, 1987; Konishio and Haber, 1994), which is typically involved in emotional processing, and projects to brain-stem regions involved in autonomic control (Terreberry and Neafsey, 1983; Hurley et al., 1991).

In the present study, the most significant activation associated with hypothesis testing, even in the absence

TABLE 2

Coordinates of Significant rCBF ChangeAssociated with Making a Choice in the Hypothesis-Testing and Guessing Tasks Compared to Not Making a Choice

\begin{tabular}{|c|c|c|c|c|c|c|}
\hline \multirow[b]{2}{*}{ Region of activation } & \multirow[b]{2}{*}{ Left/right } & \multirow[b]{2}{*}{ Brodmann's area } & \multicolumn{2}{|c|}{ Talairach coordinates } & \multirow{2}{*}{$\begin{array}{l}Z \text { value (3.09 } \\
\text { for } P<0.001 \text { ) }\end{array}$} & \multirow[b]{2}{*}{$z$} \\
\hline & & & $\mathrm{x}$ & $y$ & & \\
\hline \multicolumn{7}{|l|}{ Relative activations } \\
\hline Anterior cingulate & $\mathrm{L}$ & $32 / 24$ & -4 & 28 & 30 & 3.87 \\
\hline Lateral orbitofrontal cortex & $\mathrm{R}$ & 11 & 34 & 54 & -12 & 3.78 \\
\hline \multicolumn{7}{|l|}{ Relative deactivations } \\
\hline Medial temporal gyrus & $\begin{array}{l}L \\
R\end{array}$ & $\begin{array}{l}37 \\
39\end{array}$ & $\begin{array}{r}-52 \\
28\end{array}$ & $\begin{array}{l}-56 \\
-48\end{array}$ & $\begin{array}{r}-2 \\
10\end{array}$ & $\begin{array}{l}3.99 \\
3.76\end{array}$ \\
\hline Inferior temporal gyrus & $\mathrm{R}$ & 20 & 48 & -14 & -22 & 3.76 \\
\hline Posterior cingulate & $\mathrm{R}$ & 29 & 10 & -42 & 12 & 3.76 \\
\hline Anterior frontal cortex & $R / L$ & 10 & 0 & 40 & -10 & 3.33 \\
\hline
\end{tabular}


of choice, was in the cerebellar vermis extending laterally to the cerebellar hemispheres on both sides, which adds to the evidence implicating this structure in higher cognitive function (see Schmahmann, 1996, for review). Studies of patients with cerebellar damage have demonstrated neuropsychological deficits on a range of tasks, including learning and error detection (Fiez et al., 1992), planning (Grafman et al., 1992), and visual spatial ability (Botez et al., 1989), all of which are component processes of our paradigm. Functional neuroimaging studies have also pointed to a critical role for the cerebellum in cognitive processes, including those engaged by the present paradigm: mental imagery (Mellet et al., 1995; Parsons et al., 1995), cognitive flexibility (Kim et al., 1994), sensory discrimination (Gao et al., 1996), and working memory (Klingberg et al., 1995). The exact role of the cerebellum in these diverse and complex cognitive functions remains unclear. A recent parsimonious suggestion is that it is involved in sensory discrimination (Gao et al., 1996), which is an integral component of most functional imaging paradigms. Our paradigm places particularly stringent demands on sensory discrimination processes, requiring subjects to discriminate complex visuospatial patterns on the basis of subtle configurational differences.

\section{TABLE 4}

Coordinates of Significant rCBF ChangeAssociated with Choice Compared to No Choice in the Hypothesis-Testing Task and in the Guessing Task (Simple Main Effects)

\begin{tabular}{|c|c|c|c|c|c|c|}
\hline \multirow{2}{*}{$\begin{array}{l}\text { Region of } \\
\text { activation }\end{array}$} & \multirow{2}{*}{$\begin{array}{l}\text { Left/ } \\
\text { right }\end{array}$} & \multirow{2}{*}{$\begin{array}{l}\text { Brodmann's } \\
\text { area }\end{array}$} & \multicolumn{3}{|c|}{$\begin{array}{l}\text { Talairach } \\
\text { coordinates }\end{array}$} & \multirow{2}{*}{$\begin{array}{c}\text { Z value } \\
\text { (3.09 for } \\
\text { P }<0.001)\end{array}$} \\
\hline & & & $x$ & $\mathrm{y}$ & z & \\
\hline \multicolumn{7}{|l|}{ Hypothesis testing } \\
\hline \multicolumn{7}{|l|}{ Activations } \\
\hline \multicolumn{7}{|l|}{ Anterior cingu- } \\
\hline late & $\mathrm{L}$ & $32 / 24$ & -4 & 26 & 30 & 3.99 \\
\hline Postcentral gyrus & $\mathrm{R}$ & 4 & 28 & -6 & 48 & 3.68 \\
\hline Precuneus & $\mathrm{R} / \mathrm{L}$ & 7 & 2 & -52 & 52 & 3.20 \\
\hline \multicolumn{7}{|l|}{ Deactivations } \\
\hline $\begin{array}{l}\text { Posterior cingu- } \\
\text { late }\end{array}$ & $\mathrm{R}$ & 29 & 10 & -42 & 12 & 4.42 \\
\hline \multicolumn{7}{|l|}{ Guessing } \\
\hline \multicolumn{7}{|l|}{ Activations } \\
\hline $\begin{array}{l}\text { Lateral orbito- } \\
\text { frontal cortex } \\
\text { Deactivations }\end{array}$ & $\mathrm{R}$ & 11 & 30 & 52 & -14 & 3.20 \\
\hline $\begin{array}{l}\text { Medial temporal } \\
\text { gyrus }\end{array}$ & $L$ & 37 & -50 & -62 & 8 & $4.92 *$ \\
\hline \multicolumn{7}{|l|}{ Inferior temporal } \\
\hline gyrus & $\mathrm{R}$ & 20 & 46 & -14 & -30 & 4.30 \\
\hline \multicolumn{7}{|l|}{ Anterior pre } \\
\hline
\end{tabular}

Note. Activations are reported for descriptive purposes which reach a statistical threshold of $\mathrm{P}<0.001$ uncorrected, but those which reach corrected significance at $\mathrm{P}<0.05$ are marked $(*)$.

\section{TABLE 5}

Coordinates of Significant Activations Associated with Hypothesis Testing Compared to Guessing When a Choice is Required and When It Is Not (Simple Main Effects)

\begin{tabular}{|c|c|c|c|c|c|c|}
\hline \multirow{2}{*}{$\begin{array}{l}\text { Region of } \\
\text { activation }\end{array}$} & \multirow{2}{*}{$\begin{array}{l}\text { Left/ } \\
\text { right }\end{array}$} & \multirow{2}{*}{$\begin{array}{c}\text { Brodmann's } \\
\text { area }\end{array}$} & \multicolumn{3}{|c|}{$\begin{array}{l}\text { Talairach } \\
\text { coordinates }\end{array}$} & \multirow{2}{*}{$\begin{array}{l}\text { Z value } \\
\text { (3.09 for } \\
P<0.001)\end{array}$} \\
\hline & & & $x$ & $\mathrm{y}$ & $\mathrm{Z}$ & \\
\hline \multicolumn{7}{|l|}{ Choice } \\
\hline Anterior cingulate & $\mathrm{L}$ & 6 & -6 & 24 & 48 & 3.61 \\
\hline Postcentral gyrus & $\mathrm{R}$ & 4 & 28 & -4 & 48 & 3.81 \\
\hline $\begin{array}{l}\text { Precuneus } \\
\text { Medial frontal }\end{array}$ & $\mathrm{L} / \mathrm{R}$ & 7 & -2 & -64 & 56 & 4.50 \\
\hline gyrus & $\mathrm{L}$ & 44 & -40 & 52 & 2 & 3.54 \\
\hline Thalamus & $\mathrm{R}$ & & 8 & -14 & 12 & 3.68 \\
\hline Cerebellar vermis & $\mathrm{L} / \mathrm{R}$ & & -2 & -68 & -18 & 4.66 \\
\hline Lateral cerebellum & $\mathrm{R}$ & & 26 & -54 & -32 & 4.05 \\
\hline & $\mathrm{L}$ & & -36 & -74 & -28 & 3.61 \\
\hline \multicolumn{7}{|l|}{ No choice } \\
\hline Anterior cingulate & $\mathrm{L}$ & 6 & -4 & 22 & 48 & 3.73 \\
\hline Cerebellar vermis & $\mathrm{L} / \mathrm{R}$ & & 2 & -54 & -46 & 3.65 \\
\hline
\end{tabular}

Perhaps the most surprising finding of this study was the relatively limited extent of the prefrontal activations. Previous PET studies of executive tasks have reported extensive activations in regions including the DLPFC (Petrides et al., 1993; Berman et al., 1995; Owen et al., 1996; Baker et al., 1996; Rao et al., 1996). In our study, hypothesis testing was associated with activation in left ventrolateral prefrontal frontal cortex (VLPFC) but no dorsolateral activation was observed, even when the significance threshold was reduced to uncorrected $\mathrm{P}<0.01$. One possible explanation is that the DLPFC was equally activated in both the hypothesis-testing and the control guessing task. There is evidence that simple response selection (as in guessing) results in activation of the DLPFC (Frith et al., 1991). However, it seems unlikely that simple guessing would activate this region to the sameextent as the much more demanding hypothesis-testing task, particularly as the stimuli in our experiment remained constant throughout the guessing task to prevent implicit hypothesis testing. Also the simple main effect of choice in the control task was not associated with activation of the DLPFC, suggesting that simple response selection did not activate this region in the present study. It could also be argued that the hypothesis-testing task was so complex that subjects may have resorted to guesswork. However, debriefing indicated otherwise and all subjects produced at least two plausible hypotheses for each test run.

There has been much recent debate concerning the relative roles of the DLPFC and VLPFC, the latter of which was activated in the present study. Petrides $(1994,1996)$ has argued that the two regions subserve different levels of involvement in working memory. 
Mid-VLPFC, interacting with posterior cortical areas, is proposed to subserve various "first order executive processes," including the active selection, comparison, and judgment of stimuli held in long- and short-term memory. The DLPFC by contrast, is required when several pieces of information in working memory must be manipulated and monitored on the basis of task requirements. Support for this hypothesis was provided by several studies of working memory (Petrides et al., 1993, 1995; Doyon et al., 1996). When subjects described their approach to the hypothesis-testing problems in the present study, they all reported an essentially sequential approach to the problems. Thus, they selected one possible hypothesis then compared and judged incoming stimuli against it until there was evidence to reject it, at which point a new hypothesis was generated. There is some empirical evidence that subjects do indeed adopt this approach to complex hypothesis-testing tasks (Bower and Trabasso, 1964). This strategic approach to the problem may explain the lack of DLPFC activation; had subjects been monitoring a number of possible hypotheses "on-line" simultaneously (as they may do in, for example, in the simpler Wisconsin Card Sort Test), then we would predict DLPFC activation.

The VLPFC activation in this study was left-sided. Left VLPFC activation has typically been associated with verbal working memory (Petrides et al., 1995), while visuospatial tasks are associated with right-sided activation (Doyon et al., 1996). While the present task involves visuospatial stimuli, the subjects may well have generated their hypotheses in verbal code, especially as the requirement to describe the hypotheses after each run explicitly encouraged subjects to do so. Activation was also observed the precuneus, a region which has been associated with representation of shape and spatial location (Baker et al., 1994; Haxby et al., 1991), visual imagery (Roland and Gulyas, 1994), and memory-related imagery (Fletcher et al., 1995a,b). In the reports of Fletcher et al. (1995a,b), increasing the imageability of words in a paired associate learning task was associated with increased focal activation of the precuneus. In the present study, a verbally coded hypothesis corresponds to a visuospatial image which can be used to facilitate the comparison of incoming stimuli with the current hypothesis. This process may besubserved by the concurrent activation of left VLPFC and precuneus.

The other noteworthy prefrontal activation observed in this study was in the right lateral orbitofrontal cortex in association with choice, regardless of task type. We had hypothesized this activation on the basis of findings that patients with lesions to orbitofrontal cortex show deficits in behavior involving aspects of risk-taking and decision-making in incompletely specified situations (Bechara et al., 1994, 1996; Damasio,
1994). Strikingly, these studies reported that patients with orbitofrontal lesions can typically report the contingencies which apply in gambling tasks but may fail to act upon them. In the present study orbitofrontal activation was not associated with hypothesis testing but only with the requirement to make a choice, which also suggests a key role for this region in cognitive processing related to behavioral choice.

In conclusion, we show that a wide network of structures including dorsal anterior cingulate, ventrolateral prefrontal cortex, cerebellum, and posterior parietal cortex is activated by a visuospatial hypothesistesting task compared to a simple control task. The experimental task is a complex one involving a number of subprocesses which could be dissociated in subsequent studies. More specifically though, we demonstrated that the requirement to make a choice rather than a specified response was associated with augmentation of activation of a relatively more ventral region of the anterior cingulate. This finding crucially suggests functional specialization within this complex cognitive domain. Our findings in this study al so add to recent evidence suggesting a role for the cerebellum in cognition as well as confirming the importance of specific cognitive requirements of tasks in determining which regions of prefrontal cortex are activated. The modulation of task-specific activations by the require ment to make a choice further stresses this point. A simple manipulation of the way in which hypothesistesting performance is measured had significant effects on the neural substrates of the task. When subjects are required to commit themselves to a cognitive hypothesis by making a choice, this has significant neural consequences that we propose represent different processing requirements, in particular processing related to the evaluation of outcomes.

\section{ACKNOWLEDGMENTS}

R.J .D. is supported by the WellcomeTrust. Weare grateful to Chris Frith and Karl Friston for their hel pful comments and discussion.

\section{REFERENCES}

Andreasen, N. C., Rezai, K., Alliger, R., Swayze, V. W., Flaum, M., Kirchner, P., Cohen, G., and O'Leary, D. S. 1992. Hypofrontality in neuroleptic-naive patients and in patients with chronic schizophre nia. Assessment with xenon 133 single-photon emission computed tomography and the Tower of London. Arch. Gen. Psychiatry 49:943-958.

Baker, S. C., Rogers, R. D., Owen, A. M., Frith, C. D., Dolan, R. J ., Frackowiak, R. S. J ., and Robbins, T. W. 1996. Neural systems engaged by planning: A PET study of the Tower of London task. Neuropsychologia 6:515-526.

Bechara, A., Damasio, A. R., Damasio, H., and Anderson, S. W. 1994. Insensitivity to future consequences following damage to human prefrontal cortex. Cognition 50:7-15.

Bechara, A., Tranel, D., Damasio, H., and Damasio, A. R. 1996. 
Failure to respond autonomically to anticipated future outcomes following damage to the prefrontal cortex. Cereb. Cortex 6:215-225.

Berman, K. F., Ostrem, J . L., Randol ph, C., Gold, J ., Goldberg, T. E., Coppola, R., Carson, R. E., Herscovitch, P., and Weinberger, D. R. 1995. Physiological activation of a cortical network during performance of the Wisconsin Card Sorting Test: A positron emission tomography study. Neuropsychologia 33:1027-1046.

Botez, M. I., Botez, T., Elie, R., and Attig, E. 1989. Role of the cerebellum in complex human behaviour. Ital. J. Neurol. Sci. 10:291-300.

Bower, G. H., and Trabasso, T. 1964. Presolution reversal and dimensional shifts in concept identification. J . Exp. Psychol . 67:398399.

Cherry, E. C. 1979. Human communication: Values, choice and courage in a world of chance. In Uncertain Outcomes (C. R. Bell, Ed.). MTP Press, Lancaster.

Cohen, J . 1972. Psychological Probability or theArt of Doubt. Allen \& Unwin, London.

Corbetta, M., Miezin, F. M., Shulman, G. L., and Petersen, S. E. 1993. A PET study of visuospatial attention. J . Neurosci. 13:1202-1226.

Damasio, A. R. 1994. Descartes' Error. Putnam, New York.

Doyon, J ., Owen, A. M., Petrides, M., Sziklas, V., and Evans, A. C. 1996. Functional anatomy of visuomotor skill learning in human subjects examined with positron emission tomography. Eur. J . Neurosci. 8:637-648.

Dum, R. P., and Strick, P. L. 1991. The origin of the corticospinal projections from the premotor areas in the frontal lobe. J . Neurosci. 11:667-688.

Duvernoy, H. M. 1991. The Human Brain: Surface, ThreeDimensional Sectional Anatomy and MRI. Springer-Verlag, New York.

Fiez, J . A., Petersen, S. E., Cheney, M. K., and Raichle, M. E. 1992. I mpaired non-motor learning and error detection associated with cerebellar damage. Brain 115:155-178.

Fletcher, P. C., Frith, C. D., Baker, S. C., Shallice, T., Frackowiak, R. S. J., and Dolan, R. J. 1995a. The mind's eye-Precuneus activation in memory-related imagery. Neurol mage 2:195-200.

Fletcher, P. C., Frith, C. D., Grasby, P. M., Shallice, T., Frackowiak, R. S. J ., and Dolan, R. J . 1995b. Brain systems for encoding and retrieval of auditory-verbal memory: An in vivo study in humans. Brain 118:401-416.

Friston, K. J ., Holmes, A. P., Worsley, K. J ., Poline, J -B., Frith, C. D., and Frackowiak, R. S. J. 1995. Statistical parametric maps in functional imaging: A general approach. Hum. Brain Mapping 2:189-210.

Frith, C. D., Friston, K. J ., Liddle, P. F., and Frackowiak, R. S. J . 1991. Willed action and the prefrontal cortex in man: A study with PET. Proc. R. Soc. London B244:241-246.

Gao, J -H., Parsons, L. M., Bower, J . M., Xiong, J ., Li, J ., and Fox, P. T. 1996. Cerebellum implicated in sensory acquisition and discrimination rather than motor control. Science 272:545-547.

Goldberg, T. E., Berman, K. F., Randolph, C., Gold, J. M., and Weinberger, D. R. 1996. I solating the mnemonic component in spatial delayed response: A controlled PET ${ }^{15} \mathrm{O}-$-labeled water regional cerebral blood flow study in humans. Neurol mage 3:6978.

Grafman, J ., Litvan, I., Massaquoi, S., Stewart, M., Sirigu, A., and Hallett, M. 1992. Cognitive planning deficit in patients with cerebellar atrophy. Neurol ogy 42:1493-1496.

Haxby, J . V., Grady, C. L., Horvitz, B., Ungerleider, L. G., Mishkin, M., Carson, R. E., Herscovitch, P., Schapiro, M. B., and Rapoport, S. I. 1991. Dissociation of object and spatial visual processing pathways in human extrastriate cortex. Proc. Natl. Acad. Sci. USA 88:1621-1625.

Hurley, K. M., Herbert, H., Moga, M. M., and Saper, C. B. 1991.
Efferent projections of the infralimbic cortex of the rat. J . Comp. Neurol. 308:249-276.

Kim, S. G., Ugurbil, K., and Strick, P. L. 1994. Activation of a cerebellar output nucleus during cognitive processing. Science 265:949-951.

Klingberg, T., Roland, P. E., and Kawashima, R. 1995. The neural correlates of the central executive function during working memory-A PET study. Hum. Brain Mapping (Suppl.) 1:414.

Konishio, K., and Haber, S. N. 1994. Primate cingulostriatal projection: Limbic striatal vs. sensorimotor striatal input. J. Comp. Neurol. 350:337-356.

Mellet, E., Crivello, F., Tzourio, M., J oliot, M., Petit, L., Laurier, L., Denis, M., and Mazoyer, B. 1995. Construction of mental images based on verbal description: Functional neuroanatomy with PET. Hum. Brain Mapping (Suppl.) 1:273.

Morecraft, R. J ., and Van Hoesen, G. W. 1992. Cingulate input to the primary and supplementary motor cortices in the rhesus monkey: Evidence for somatotopy in areas $24 \mathrm{c}$ and 23c. J. Comp. Neurol. 322:471-489.

Owen, A. M., Doyon, J ., Petrides, M., and Evans, A. C. 1996. Planning and spatial working memory: A positron emission tomography study in humans. Eur. J . Neurosci. 8:353-364.

Pandya, D. N., and Yeterian, E. H. 1996. Comparison of prefrontal architecture and connections. Philos. Trans. R. Soc. London B 351:1423-1432.

Pardo, J . V., Pardo, P. J ., J aner, K. W., and Raichle, M. E. 1990. The anterior cingulate cortex mediates processing selection in the Stroop attentional conflict paradigm. Proc. Natl. Acad. Sci. 87:256259.

Parsons, L. M., Fox, P. T., Downes, J. H., Glass, T., Hirsch, T. B., Martin, C. C., J erabak, P. A., and Lancaster, J . L. 1995. Use of implicit motor imagery for visual shape discrimination as revealed by PET. Nature 375:54-58.

Paus, T., Petrides, M., Evans, A. C., and Meyer, E. 1993. Role of human anterior cingulate cortex in the control of oculomotor, manual and speech responses: A positron emission tomography study. J . Neurophysiol. 2:453-469.

Petersen, S. E., Fox, P. T., Posner, M. I., Mintun, M., and Raichle, M. E. 1988. Positron emission tomographic studies of the cortical anatomy of single-word processing. Nature 331:585-589.

Petrides, M. 1994. Frontal lobes and working memory. In Handbook of Neuropsychology (F. Boller and J. Grafman, Eds.), Vol. 3, pp. 75-90. Elsevier, Amsterdam.

Petrides, M. 1996. Specialized systems for the processing of mne monic information within the primate frontal cortex. Philos. Trans. R. Soc. London B 351:1455-1462.

Petrides, M., Alivisatos, B., Evans, A. C., and Meyer, E. 1993a. Dissociation of human mid-dorsolateral from posterior dorsolateral frontal cortex in memory processing. Proc. Natl. Acad. Sci. USA 90:873-877.

Petrides, M., Alivisatos, B., Evans, A. C., and Meyer, E. 1993b. Functional activation of the human frontal cortex during the performance of verbal working memory tasks. Proc. Natl. Acad. Sci. USA 90:878-882.

Petrides, M., Alivisatos, B., and Evans, A. C. 1995. Functional activation of human ventrolateral frontal cortex during mnemonic retrieval of verbal information. Proc. NatI. Acad. Sci. USA 92:58035807.

Posner, M. I., Petersen, S. E., Fox, P. T., and Raichle, M. E. 1988. Localisation of cognitive function in the human brain. Science 240:1627-1631.

Rao, S. M., Bobholz, J . A., Woodley, S. J ., Rosen, A. C., Hammeke, T. A., Fuller, S. A., Cunningham, J . M., Cox, R. W., Binder, J . R., and 
Stein, E. A. 1996. Functional neuroanatomy of human concept formation skills. Neurol mage 3:S239. [Abstract]

Roland, P. E., and Gulyas, B. 1994. Visual imagery and visual representation. Trends Neurosci. 17(7):281-287.

Schmahmann, J. D. 1996. From movement to thought: Anatomic substrates of the cerebellar contribution to cognitive processing. Hum. Brain Mapping 4:174-198.
Talairach, J ., and Tournoux, P. 1988. Coplanar Stereotactic Atlas of theH uman Brain. Thieme, Stuttgart.

Terreberry, R. R., and Neafsey, E. J . 1983. Rat medial frontal cortex: A visceral motor region with direct projection to a solitary nucleus. Brain Res. 278:245-249.

Vogt, B. A., and Pandya, D. N. 1987. Cingulate cortex of the rhesus monkey. II . Cortical afferents. J . Comp. Neurol. 262:271-289. 